\title{
Analysis on Campus Environment Factors in Influencing Cultivation of Postgraduate students' Innovative Personality ----Taking China University of Petroleum, Beijing Campus (CUP), as example
}

\author{
Liu Yunqiu ${ }^{1}$ Du Chenxi ${ }^{2}$ Guo Xiaojie $^{3}$ \\ ${ }^{1}$ China University of Petroleum Retired Sector, Beijing 102249 \\ ${ }^{2}$ China University of Petroleum, Higher Education Institute,Beijing 102249, \\ 3 China University of Petroleum, College of Petroleum Engineering Beijing 102249, \\ lyq0911@sina.com,duchenxi07@163.com
}

\begin{abstract}
Innovative personality as non-intelligence factor plays an important role in stimulating the innovative potential of top innovative talents, which not only calls for internal motivation but also needs specific external environments, including the campus physical environment, psychological environment and cultural environment. This paper first discusses the meaning of innovative personality and the form of campus environment which influences the cultivation of the personality, and then carries quantitative analysis on abstract campus environment factors through questionnaires thus reveals the current situation and the existing problems of campus innovative environment of China University of Petroleum, Beijing Campus (CUP). Based on these problems, the author put forward the corresponding countermeasures to optimize the environment of campus innovation from the aspects of school administrators, teachers and postgraduate students respectively.
\end{abstract}

Key Words - Innovative Personality, postgraduate students, environment factor

Building innovative country and cultivating innovative talents are significant strategic basis of China's socialist modernization drive. Innovative Personality (hereafter called IP) as non-intellectual factor plays an important role in stimulating the innovative potential of top innovative talents, which not only calls for internal motivation but also needs specific external environments. The author thinks that all environmental factors are interrelated and any missing or immature factors will influence the cultivation of postgraduate students' IP. So to improve the innovative environment of university is very important to the cultivation of innovative talents

\section{I . Theoretical analysis of IP and environmental factors}

\section{A . Conception and core traits of IP}

One's innovative potential is inspired by both intellectual and non-intellectual factors. Human ingenuity or creative thinking as an innovative potential belongs to intellectual factors, while the IP belongs to the non-intellectual factors. In innovative activities, intellectual factors determine whether a person has the ability to do, while personality factors determine whether he wants to do and can stick it out, but the final results are combination of the two ${ }^{[1]}$. IP refers to creative mental quality which is peculiar to the individual who is not superstitious, not bland and indomitable. It is genetic and can also be acquired in one's latter life.

Personality is a broad and complex system which is composed of many factors interacting with each other. Different traits in personality play different roles in the innovative activities, and among them factors including curiosity, confidence, independence and perseverance are fundamental and decisive to the innovative activities. They are also core traits in one's personality ${ }^{[2]}$.

\section{B. Environmental factors in influencing postgraduate students' cultivation of IP}

University environment factors influence the cultivation of postgraduate students' IP. This paper divides the factors into three detailed aspects such as physical environment factors, psychological factors, and cultural environment factors to investigate, analyze and discuss on the basis of the postgraduate education environment provided on campus and in accordance with postgraduate students' study, activities and life circle.

\section{1) Physical environment factors.}

Physical environment mainly refers to the natural environment on campus, campus facilities and dormitory environment. Making a general view of those famous overseas universities such as Oxford, Cambridge and Harvard, we will be impressed by their rich cultural deposits shown through the beautiful natural scenery and unique architectural styles. Dipping into those environment, our innovative thinking will be inspired. And the convenient campus facilities and advanced laboratory equipments serve as essential basis to the forming and development of IP.

2) Psychological environment factors.

Psychological environment is a kind of soft environment, including two aspects namely interpersonal relationship factors and spirit of cooperation. On the one hand, in terms of interpersonal factors, harmonious and close relationship between classmates, teachers and students is advantageous to the communication of different views, which will inspire innovative thinking and generate new ideas. On the other hand, 
due to the trend that disciplines become more and more diverse, interrelated and specialized, it is crucial to take various knowledge into account and to strengthen team cooperation consciousness in the process of innovative activities.

\section{3) Cultural environment factors.}

Just like psychological environment, cultural environment is also a kind of soft environment, it mainly includes three aspects such as institutional culture, teaching culture and humane environment. Institutional culture is a series of rules and regulations made by universities to encourage postgraduate students to participate into innovative activities, as well as norms of behaviours and practices between postgraduate students and teachers and universities ${ }^{[3]}$. Humane environment is mainly reflected in the cultural atmosphere and the spirit of innovation on campus such as ethos of the school and school motto.

\section{II . Investigation and analysis of environmental factors influencing postgraduate students' IP cultivating- taking CUP, as example}

China University of Petroleum, Beijing Campus (CUP) is one of the key universities attaching to the Ministry of Education of China and is also one of universities with graduate school. CUP features in petroleum, gives priority to engineering and coordinates multidisciplinary development. Until October, 2012, CUP has 11 colleges(faculties) and 4 affiliated research institutes, including College of Geosciences, College of Petroleum Engineering, and College of Chemical Engineering, etc. At present, the total enrolled students is more than 13,000, among which postgraduate students accounts for about $36 \%$. This paper uses the questionnaire method. There are a total of 19 structural topics and 2 open topics, with 5 levels of scoring criteria. Through random sampling, the author handed out 90 questionnaires, recycling 85 with 5 scratch volumes. Thus the recycling rate is $94.4 \%$ and the effective rate is $97.6 \%$. And among the 90 postgraduate students, 55 are male students accounting for $75.0 \%$ while 28 are female students accounting for $33.7 \%$. In addition, there are 62 engineering students and 21 liberal arts students accounting for $75.0 \%$ and $25.0 \%$ respectively.

\section{A. . Survey results on the environment factors in influencing the cultivation of postgraduates' IP in CUP}

1) The overall level of postgraduate innovative environment

The survey shows that according to the level 5 scoring criteria $(5,4,3,2,1)$, the score of each topic will be added, the higher the added score is, the better the innovative environment will be. By comparing the mean values (see table 1), we can find that the mean value of university students' innovative environment is slightly higher than that of the project's, but it hasn't reach the higher level even to speak of the optimal level. From table 2, it is easy to find out that the mean values of campus environment, campus facilities and equipments, dormitory environment, interpersonal relationship, cooperative spirit, institutional culture, teaching culture and humane environment are 7.193, 7.293, 6.651, 8.374, 7.590, 10.723, 7.590, 10.723 respectively. And among them almost all the factors are below the higher level, especially the dormitory environment and the teaching culture remain relatively low level, with an exception of interpersonal relationship.

Table 1 Descriptive Statistics on Environment Factors in Influencing the Cultivation of Postgraduates' IP , CUP

\begin{tabular}{|c|c|c|c|c|}
\hline & $\begin{array}{c}\text { Physical } \\
\text { Environ-ment }\end{array}$ & $\begin{array}{c}\text { Psychological } \\
\text { Environment }\end{array}$ & $\begin{array}{c}\text { Cultural } \\
\text { Environm-ent }\end{array}$ & $\begin{array}{c}\text { University's } \\
\text { Innovative } \\
\text { Environment } \\
\text { (Total) }\end{array}$ \\
\hline $\begin{array}{c}\text { People } \\
\text { Number }\end{array}$ & 83 & 83 & 83 & 83 \\
\hline $\begin{array}{c}\text { Mean } \\
\text { Value }\end{array}$ & 21.1361 & 15.9639 & 31.7032 & 68.8032 \\
\hline $\begin{array}{c}\text { General } \\
\text { Level }\end{array}$ & 18 & 12 & 27 & 57 \\
\hline $\begin{array}{c}\text { Higher } \\
\text { Level }\end{array}$ & 24 & 16 & 36 & 76 \\
\hline $\begin{array}{c}\text { Optimal } \\
\text { Level }\end{array}$ & 30 & 20 & 45 & 95 \\
\hline
\end{tabular}

Table 2 Descriptive Statistics on All the Dimensional Factors in Influencing the Cultivation of Posgraduates' IP, CUP

\begin{tabular}{|c|c|c|c|c|c|c|c|c|}
\hline & \multicolumn{3}{|c|}{$\begin{array}{c}\text { Physical } \\
\text { Environment }\end{array}$} & \multicolumn{2}{c|}{$\begin{array}{c}\text { Psychological } \\
\text { Environment }\end{array}$} & \multicolumn{3}{c|}{ Cultural Environment } \\
\hline & CE & CFAE & DE & IR & CS & IC & TC & HE \\
\hline $\begin{array}{c}\text { People } \\
\text { Number }\end{array}$ & 83 & 83 & 83 & 83 & 83 & 83 & 83 & 83 \\
\hline $\begin{array}{c}\text { Mean } \\
\text { Value }\end{array}$ & 7.193 & 7.293 & 6.651 & 8.374 & 7.590 & 10.723 & 13.855 & 7.121 \\
\hline $\begin{array}{c}\text { General } \\
\text { Value }\end{array}$ & 6 & 6 & 6 & 6 & 6 & 9 & 12 & 6 \\
\hline $\begin{array}{c}\text { Higher } \\
\text { Level }\end{array}$ & 8 & 8 & 8 & 8 & 8 & 12 & 16 & 8 \\
\hline $\begin{array}{c}\text { Optimal } \\
\text { Level }\end{array}$ & 10 & 10 & 10 & 10 & 10 & 15 & 20 & 10 \\
\hline
\end{tabular}

Note1: CE ,CFAE,DE,IR,CS,IC,TC,HE is short of Campus Enviroment, Campus Facilities and Equipments, Domitory Environment, Interpersonal

Relationship, Cooperative Spirit, Institutional Culture, Teaching Culture, Humane Environment respectively.

2) Environment factors in influencing the cultivation of postgraduates' IP in CUP exist significant differences in research fields

As for the majors of liberal arts and engineering, the $T$ test result for the factor of campus facilities and equipments is 2.473 and the sig value(T statistic concomitant probability) is 0.016 which is less than the significance level of 0.05 . And as to other dimensional factors, there are not significant differences in dividing the majors of liberal arts and engineering(see table 3). There are relatively big differences between the majors of liberal arts and engineering on terms of 
the institutional factor and teaching cultural factor. The main reason for that is the study of engineering students has a relatively higher demand for practical abilities, laboratories and experiment facilities and equipments while the liberal arts students pay more attention to the application of theoretical knowledge and have lower demand for experiment facilities and equipments. Generally speaking, liberal arts students are much more satisfied with the factor of campus facilities and equipments.

Table 3 Variance Analytical Table on the Major Differences of specialty for Campus Innovative Environment, CUP (Independent Samples T Test)

\begin{tabular}{|c|c|c|c|c|c|c|c|c|}
\hline & \multicolumn{2}{|c|}{$\begin{array}{c}\text { Physical } \\
\text { Environment }\end{array}$} & \multicolumn{2}{c|}{$\begin{array}{c}\text { Psychological } \\
\text { Environment }\end{array}$} & \multicolumn{3}{|c|}{ Cultural Environment } \\
\hline & CE & CFAE & DE & IE & CS & IC & TC & HE \\
\hline Engineering & 7.210 & 7.557 & 6.807 & 8.419 & 7.694 & 10.952 & 13.742 & 7.210 \\
\hline Liberal Arts & 7.143 & 6.524 & 6.191 & 8.238 & 7.286 & 10.048 & 14.191 & 6.857 \\
\hline T & 0.176 & $2.473 *$ & 1.386 & 0.506 & 0.977 & 1.450 & -0.635 & 0.846 \\
\hline Sig & 0.861 & 0.016 & 0.170 & 0.614 & 0.332 & 0.151 & 0.527 & 0.400 \\
\hline
\end{tabular}

Note 2: see Note 1

$B$. Analysis of problems for the environment factors in influencing the cultivation of postgraduates' innovative personalities in CUP

1) On terms of the university's physical environment, the main problem is the lack of advancement and openness for the campus facilities and equipments,

Most of the students complain that the library's electronic resources is deficient, the update speed of books is slow and the available seats are less than needed. In addition, the campus network speed is slow, the wireless network cannot be popularized and some laboratories and equipments can't be completely open to the students which makes the resources can't be fully used.

2) On terms of psychological environment, postgraduate students lack the spirit of teamwork

As the survey shows, excepts for the teachers' requirements, the students seldom actively take the form of teamwork to finish study tasks during their learning or research activities. That's mainly because the students' cooperation consciousness is not strong. Besides there are few innovative activities on campus which makes the students don't have enough opportunities to practise their spirit of teamwork.

3) On terms of the university's cultural environment, the teaching culture lacks vigor.

From the survey, we can find out the hindrances for the development of students' divergent thinking and cultivation of their IP such as many engineering students complain that the teaching content is old, the classroom atmosphere is dull, the teachers tend to use simple and direct teaching method rather than heuristic and problem-based teaching methods and the university lays too much emphasis on the results of examinations.

\section{Several countermeasures to optimize the campus innovative environment of postgraduate students in CUP}

A . Educational concepts of administrators in colleges and universities should shift from power to service and quality management should be strengthened

1) To guarantee the construction of the university's innovative environment from the policy level

Firstly, the university should make rules to guarantee the innovation and research funds of postgraduate students. Secondly, the university should perfect the incentive mechanism to improve students' innovative enthusiasm and adjust the policies according to the effects at any time in order to ensure the consistency with the goal of improving the university's innovative environment.

2) The university should hold student--oriented service concept on the construction of campus environment

The university leaders should attach great importance to the construction of students' innovative environment, to provide hardware facilities on the basis of the students' needs, and to update all kinds of equipments and facilities so as to build a good environment for the cultivation of innovative talents. And based on the existing problems, the university should improve the campus network speed, improve the use efficiency of experiment equipments, accelerate the modern construction of university library and update book resources in time. Further, the university should strengthen cooperative innovation and perfect the mechanism of university-enterprise cooperation $^{[4]}$

$B$. The teachers should innovate teaching methods and strengthen the supervisor's responsibility system

1) Adopt problem-based and heuristic teaching methods and try to create a relaxed and happy classroom atmosphere

Teachers should adopt heuristic and problem-based teaching methods and avoid the inculcating teaching method so as to inspire students to explore. As for students' innovation points of view or ideas, teachers should give guidance and encouragement rather than mockery or authoritative negation so that the students are willing to think in an innovative way of thinking over time.

2) Update the teaching materials and introduce the forefront contents in the disciplinary field in time.

The teacher should pay attention to the update of teaching materials and the introduction of forefront contents in the disciplinary field timely and properly connect the teaching contents with actual problems so that the students' horizons 
can be broadened and they can benefit from what have learned. In addition, we should strengthen the tutor's responsibility system and promote communication between tutors and students 。

C. Postgraduate students should explore actively, establish innovation ideal and promote the construction of university innovative environment.

1) Establish the scientific truth-seeking spirit of innovation which asks the students shouldn't succumb to the books, superiors and authorities.

The participation of postgraduate students into the construction of campus innovative environment is more needed, thus the students should consciously cultivate their strong will, confidence and interests so as to make themselves good at discovering problems. In addition, the students should have the courage to use critical and skeptical spirits to deal with problems and shouldn't succumb to books and authorities.

2) Establish extracurricular learning team, develop teamwork spirit and cooperation consciousness

By establishing extracurricular study group, the students can not only complete the learning activities but also can show their adept aspects. Besides, they can help and cooperate with each other in the learning process which will improve efficiency as well as improve the ability of cooperation between members.
3) Actively participate in social practices and all kinds of innovation activities to make them exercised in practice

Social practices can bring about what the university, the class and the book can't provide. Therefore, postgraduates should actively cultivate their abilities to participate into social activities to make theory and practice, innovation and practice combined so that good university ethos can be formed, the construction of university innovation environment can be further enhanced and more students can be inspired and benefited.

\section{Acknowledgement}

We would like to express sincere thanks to some supervisors for their help and guidance. And also we want to thank all the respondents for helping fulfill this survey.

\section{References}

[1] Zhang Xiaoming, Xi Chunyuan. Research on College Students' Innovative Personality Traits. Higher Education Research, 2002(03):80-81

[2] Wei Qiaoyan. Discussion on the Cultivation of College Students' Innovative Personalities. Journal of higher education, 2003(01):45

[3] Qin Rui, Ding Songbin. Analysis on the Environment Factors in Influencing the Release of Postgraduate Students' Innovation Potential. China Higher Education Research, 2006 (2) : 47-49.

[4] Zhang Nanxing, Wang Chunchun. To Launch Collaborative Innovation and Improve the Quality of Education--an Interview for Gong Ke, President of Nankai University. Journal of University, 2012 (8) : 5-6 